\title{
Os sentidos da linguagem
}

\section{Jair Antonio de Oliveira}

- Professor no curso de Comunicação Social, Relações Públicas e Jornalismo na Universidade Federal do Paraná (UFPR)

- Doutor em Ciências da Comunicação (ECA-USP)

- Pós-doutor em Pragmática Linguística pela Universidade Estadual de Campinas (Unicamp)

- Especialista em Filosofia da Educação (PUC-PR) e Linguística (UTP) e Mestre em Linguística (UFPR)

- Coordena o grupo de Pesquisa de Mídia, Linguagem e Educação na UFPR e integra o grupo de pesquisa de Pragmática Linguística, coordenado pelo professor Dr. Kanavillil Rajagopalan, na Unicamp

- Trabalhou como assessor de imprensa e relações públicas durante dez anos na Câmara Municipal de Curitiba, onde também ocupou o cargo de diretor do Departamento de Comunicação Social na gestão 1989-1990

- jairoliveira3@ufpr.br

- jairlive.compaq@uol.com.br 
O objetivo é iniciar uma reflexão sobre a "produção de sentidos" em ambientes institucionais tendo como referência uma perspectiva Pragmática Linguística (MEY, 1993; RAJAGOPALAN, 2001, 2002). Posteriormente, explicar a "natureza" performativa e contextualizada dos usos da linguagem a fim de instituir uma "política para os performativos" que coloque sob suspeita as metáforas em uso nas instituições, estimulando os indivíduos a investigar como os hábitos linguísticos institucionais alteram e (de)formam os sentidos das palavras ordinárias, com resultados imediatos em suas vidas privadas

PALAVRAS-CHAVE: PRAGMÁTICA • SENTIDOS • INSTITUCIONAL

Abstract

The aim is of enabling a reflection on the "production of meaning" in institutional environments, having as a reference a Linguistic Pragmatics perspective (MEY, 1993; RAJAGOPALAN, 2001, 2002). Following this, of explaining the performative and contextualized "nature" of the uses of language, so as to institute a "policy for the performables" that can question the metaphors used by the institutions, encouraging individuals to investigate how institutional linguistics habits can alter and (de)form the meaning of ordinary words, with immediate results in their private lives.

KEYWORDS: PRAGMATICS • MEANING • INSTITUTIONAL

\section{Resumen}

El objetivo es iniciar una reflexión sobre la "producción de sentidos" en ambientes institucionales, teniendo como referencia una perspectiva Pragmática Lingüística. Posteriormente, se explica la "naturaleza" performativa y contextualizada de los usos del lenguaje con el objetivo de instituir una "política para los performativos" que coloque bajo sospecha las metáforas en uso en las instituciones y estimule a los individuos a investigar cómo los hábitos lingüísticos institucionales alteran y (de)forman los sentidos de las palabras ordinarias, con resultados inmediatos en sus vidas privadas.

PALABRAS CLAVE: PRAGMÁTICA • SENTIDOS • INSTITUCIONAL 


\section{A representação}

Dara a maioria das pessoas é problemático imaginar que a linguagem não é um meio para representar as coisas do mundo ou expressar estados interiores. Parece tão óbvio, ou talvez seja mais fácil pensar dessa forma, que não causa estranheza o fato de as novas tecnologias, particularmente a troca de informações pela Internet, receber o rótulo de interatividade. Os meios eletrônicos constituem a versão atualizada da onisciência e onipotência divina que criou Adão. Por ser o primeiro homem, possuía uma linguagem que lhe permitia conhecer a essência das coisas e esse poder lhe outorgou o direito de atribuir um nome a cada substância ou acidente. Assim, Adão nomeava todo pássaro e todo animal do campo e, embora não perguntasse qual era a origem da língua que possuía, concebia as palavras que usava como nomes (rótulos) para as coisas. Esses nomes serviam como meios para que ele representasse os objetos que o cercavam e expressasse os seus pensamentos ou estados interiores. As palavras permitiam a Adão que as suas ideias fossem comunicáveis e as coisas do mundo representáveis, mas tanto a existência das ideias quanto das coisas era independente das palavras. Isto é, como Deus a tudo criou, as coisas e os processos (sentidos, desejos, sensações) já estavam dentro da mente do primeiro homem, em sua essência, no seu interior.

Nesse caso, mente e linguagem são independentes. Adão era capaz de perceber objetos, propriedades e relações de forma direta, sem a mediação da linguagem. Tais objetos, relações ou propriedades só se tornavam existentes na linguagem quando uma espécie de "olho interior" olhava para dentro da mente de Adão, e objetivando comunicar a Eva o que lá existe, usava a linguagem para expressar aquilo que antes de ser dizível já estava lá em seu sentido bruto (um arquétipo das coisas, uma representação do plano macro - do criador, no plano micro - a criatura).

Essa concepção de linguagem consagra a ideia de que a linguagem é um meio para representar fatos e expressar significados dados de antemão, prévios ao uso linguístico. Usar a linguagem nessa perspectiva é sempre uma questão de encontrar o já existente - algo que é o que é, independentemente de sua relação com outras coisas (OLIVEIRA, 2004).

\section{A estrutura}

Expulso do Paraíso, Adão não possui mais a realidade profunda que o permitia perceber o mundo de forma direta. Agora é uma negatividade. Onde existia uma essência, a presença divina, o logos, há uma marca de ausência, a presença de uma falta. Adão é lançado em uma interminável tarefa de preencher esse vazio com significações modeladoras que viabilizem a própria existência. As palavras (signos) não são mais nomes que carregam uma referência. São elementos vazios de significação e só ganham sentido por meio de relações de 
diferenças com outros elementos significantes que compõem o sistema (estrutura). Na concepção estrutural, a linguagem é uma espécie de matriz (asemântica) e os sentidos (valor, identidade) dos termos dessa matriz resultam de relações com outros termos que eles não são, por exemplo: cão significa cão porque não significa gato, não significa rato, e assim por diante. Saussure exemplificava isso com o jogo de xadrez, em que uma peça, por exemplo, a torre, tira a sua identidade (sentido) não do material de que é feito (pode ser de madeira, de osso ou de marfim) mas da relação de oposição que tem com as outras peças em jogo. Em suma, o signo linguístico na concepção estrutural tem um valor relativo e negativo dentro do sistema abstrato (a língua) e a relação binária (significante + significado) substitui o sistema de signos ternários (significante + significado + circunstâncias) no mundo ocidental. No que diz respeito à comunicação, uma forma de estruturalismo chamado de funcionalismo irá prevalecer. O que é considerado básico nesta concepção é a função constitutiva da "natureza" da linguagem, ou seja: há uma função centrada no emissor, outra no receptor, outra no código etc. A contribuição do funcionalismo "abriu a porta" para outros estudos sobre os usos da linguagem em situações comunicativas, mas não se libertou de uma metafísica da ausência, isto é: a "falta", nessa concepção teórica, constitui uma nova essência, uma vez que não é acidental, contingente ou empírica.

\section{A pragmática}

Há muito, a figura mítica de Adão desapareceu. No entanto, seus descendentes encarnam o fardo de retirar o sustento do suor do próprio rosto. A linguagem se transforma em um esforço deliberado e contínuo (um comportamento, uma ação) em forma de sinais gráficos, acústicos, gestuais, para dar conta das necessidades materiais e psicológicas dos seres humanos. Instaurada na dimensão sociosemiótica da linguagem, a perspectiva pragmática reflete a dinâmica do comportamento comunicativo social dos seres humanos, isto é: uma perspectiva dos vários eventos interativos em que os indivíduos se envolvem socialmente para evitar o "não ser reconhecido". Os usos da linguagem envolvem tipos de conhecimento que vão além das regras de sintaxe e semântica e não requerem apenas habilidades verbais, mas o domínio de uma ampla variedade de capacidades sociocognitivas. O usuário da linguagem deve colocar ênfase naqueles fatores que, mesmo não estando explicitamente manifestos nos textos e discursos, ainda assim, determinam o sentido desses textos e discursos através de possibilidades difíceis de verificar num primeiro momento.

É preciso considerar que os usos da linguagem são comportamentos sociais e culturais. Porém, trata-se de comportamentos intencionais. Possuem motivos que nos permitem entendê-los; permitem uma investigação desses motivos. Usar a linguagem é sempre permitir ou solicitar uma pergunta do tipo: com que fins? Como? Por quê? Quando se usa a linguagem, realiza-se uma ação (ordenada por regras) dentro de contextos sociais com determinados objeti- 
vos. Cada comunidade de falantes desenvolveu as suas próprias regras de uso; o que atesta a riqueza e a complexidade que acompanha esses usos. Não há regras melhores ou piores, pois cada conjunto de regras é o resultado da experiência histórica dos integrantes das diversas comunidades, de suas interações e intervenções no mundo. Nesse aspecto, os enunciados não são apenas instâncias articuladoras da vontade individual, mas também refletem a atmosfera social valorativa em que as pessoas estão inseridas. A pragmática ressalta a intencionalidade do sujeito, entendida aqui como um processo ativo e singular de responder às condições objetivas, e não como uma expressão de uma subjetividade pré-social.

Pensar é (in)tensionar. A intenção é sempre o desejo de alterar estados mentais do sujeito ou estados de coisas da realidade. A noção de intenção apóia-se nas leis do comportamento humano. Quanto mais sabemos acerca dessas regras, melhor podemos antecipar as intenções de uma determinada pessoa. Obviamente, os comportamentos humanos nem sempre refletem o que se esperava deles ou traduzem as regras convencionais seguidas. Isso não quer dizer que as intenções estejam codificadas no sistema interno dos indivíduos, mas que se trata de comportamentos responsivos às inúmeras solicitações que lhes são feitas enquanto seres sociais. Afirmar que há uma intenção é afirmar que são inteligíveis o agente, a ação, e um contexto ou situação operativa (um jogo de linguagem) em que o termo é usado. Em resumo, a ideia de intenção per se não existe, como também não se trata de um estado interior que pretensamente atue em termos causais. Deve ser entendida no sentido proposto por Wittgenstein (1985): meramente uma palavra usada nesta ou naquela situação para justificar um padrão de comportamento por nós elaborado e contemplado; é nesse sentido que uma ação intencional é uma ação política.

\section{A "produção" dos sentidos}

O sentido é o uso! Isso pode significar uso num sistema linguístico ou uso em uma particular situação física. Shibles (1974, p. 17) compara o termo "uso" com a atividade de disputar uma partida de xadrez ou com as operações realizadas no cálculo matemático. O uso é primordialmente uma escolha e, nessa perspectiva, o indivíduo não é, necessariamente, "produtor de sentidos" (aquele que dá origem), tarefa esta destinada ao próprio D’us. Como diz Rajagopalan (2003, p. 121): "Os seres humanos são representadores. Não homo faber, digo eu, mas homo depictor. São as pessoas que fazem as representações”. O indivíduo participa com seus pares de uma experiência histórica coletiva, em que o cognoscente e o ético estão juntos. Dessa união, resultam as representações, as "políticas dos sentidos" ou "sentidos políticos". A pessoa está sempre na ilusão de que consegue criar um discurso próprio, de que consegue amordaçar os signos em um texto, mesmo quando percebe que os outros indivíduos tecem diferentes tramas a partir do mesmo texto. Essas representações são as "formas" do sentido, os "olhares" políticos do indivíduo sobre/no mundo! 
(1) O departamento de comunicação é um hospício!

Tomada literalmente é algo risível (uma anedota, como diria Wittgenstein). No entanto, encarada como uma metáfora ou um modelo pelo qual se pode visualizar o mundo e o próprio homem, deixa de ser engraçada ou mórbida. Entender o sentido de uma metáfora é empregá-la em vários contextos e estabelecer relações com outras palavras que são usadas com frequência, ou com aquelas palavras que geralmente não são usadas. Assim, começamos a compreender determinadas regras de uso e a entender que as palavras têm sentidos como parte de um determinado universo de discurso. Esses sentidos são formas de intervenção, pois permitem que as pessoas encarem o mundo de uma forma ou de outra.

Perguntar pelo sentido de uma palavra ou frase equivale a perguntar como se usa essa palavra ou frase naquele contexto. Significa investigar o mundo em que a palavra é usada. As restrições impostas coletivamente podem delimitar o leque de escolhas linguísticas individuais nas ações interativas; mas isso apenas torna mais importante para a/na pragmática identificar como os indivíduos usam a linguagem para mudar a situação de restrição em que eles se encontram sem causar abalos nas relações e regras sociais e ao mesmo tempo dar conta de suas intenções comunicativas. Usar a linguagem não é apenas seguir um roteiro (script) nas interações, pois isso não nos leva além de uma abordagem sociolinguística (que revela como os recursos contextuais sistematicamente restringem o uso da linguagem). Mas é sempre um comportamento político, aqui entendido como as mudanças que o usuário da linguagem impõe às circunstâncias e aos interlocutores. Mesmo em locais onde há um rígido roteiro pré-determinado, como em um julgamento, onde o réu só pode se manifestar quando solicitado; em uma solenidade de formatura, onde há uma coreografia e comportamentos solenes são requeridos; em uma consulta médica; em uma reunião de acionistas da empresa etc., os aspectos da experiência individual do usuário podem ser empregados para transgredir as restrições normativas institucionais ou para singularizar o discurso no sentido de autorar, ou seja, “(...) assumir uma posição estratégica no contexto da circulação e da guerra das vozes sociais; explorar o potencial da tensão criativa da heteroglossia dialógica” (FARACO, 2003, p. 83).

Os usuários da linguagem estão sempre fazendo escolhas linguísticas e não linguísticas cujo sentido dependerá do cenário em que tais usos forem efetivados. A negociação que se instaura no momento do uso da linguagem exige que os interlocutores também focalizem a atenção na dimensão que se encontra além do que é expresso oralmente ou por meio da escrita, pois não é só o léxico que dá as informações, mas o mundo e as crenças dos envolvidos no processo. Ou seja, os sentidos dos enunciados estão relacionados à convenção sígnica e ao que está lexicalizado, mas durante uma interação tais sentidos são renegociados. Entenda-se tal ação como a possibilidade que os indivíduos encontram para transgredir ou se adequar às condições de uso vigentes nas 
diversas situações a que estão expostos e a um ajuste ou violação aos interesses e valores em pauta para a obtenção dos sentidos intencionados. Isso quer dizer que os comportamentos conversacionais não são totalmente previsíveis, pois as escolhas individuais a cada momento da sequência dialógica podem simplesmente implodir todo o roteiro. Assim, torna-se relevante indagar:

a) que escolhas (linguísticas e não-linguísticas) os usuários realizam;

b) em que contexto e circunstâncias a interação se realiza;

c) que restrições os usuários encontram ao fazer uso da linguagem nesse contexto e circunstâncias;

d) que transgressões foram constatadas;

e) que sentidos foram "produzidos".

A perspectiva pragmática permite identificar o uso da linguagem com uma explicação da inter-relação existente entre a linguagem e a situação comunicativa em que esta é tipicamente usada. Para alguns autores, trata-se de uma pragmática conversacional. Prefiro o termo interacional, pois pressupõe uma relação mais ativa e completa entre os indivíduos, em que ocorre o emprego de condições sociais e corporais que determinam os sentidos em cada ação. Nas interações, as ações comunicativas são presenças no mundo, leituras do mundo; embora a presença e a leitura nem sempre garantam um lugar comum. Ou seja, os usos da linguagem não podem ser tratados apenas em nível de atos de fala (SEARLE, 1984), em que a situação abstrata permite compatibilizar as intenções dos interlocutores sem maiores problemas. Tais comportamentos devem ser encarados como atos pragmáticos. Por exemplo, um ato de fala quando produzido em um contexto concreto é um ato pragmático. Um ato pragmático não necessita, necessariamente, ser um ato de fala:

"Atos pragmáticos são chamados pragmáticos porque estão essencialmente alicerçados no uso real da linguagem e não apenas em um uso definido por regras sintáticas ou por seleções semânticas ou restrições contextuais. Todos os atos pragmáticos são fortemente marcados pelos seus contextos: eles são duplamente derivados do contexto e limitados pelo contexto. O que significa que os atos pragmáticos são estabelecidos pelo contexto social mais amplo em que ocorrem, e que os seus propósitos são realizados sob condições baixadas por este mesmo contexto." (MEY, 1993, p. 264, tradução minha).

Os atos pragmáticos não garantem o axioma "é impossível não comunicar" como desejavam Bateson, Beavin e Watzlawick (1967), Weil e Tompakow (1973) e, atualmente Lévy (1999), que faz a apologia de que a rede digital conecta tudo e a todos e trata-se de um espaço de libertação. A complexidade dos organismos individuais com suas incontáveis redes de crenças e multiplicidade de objetivos representa a possibilidade de "não-comunicação" como regra e não como uma exceção! Isso não quer dizer simplesmente incomunicabilidade, pois apesar da relativa vagueza semântica das palavras as pessoas se comunicam; embora o sucesso desse empreendimento esteja ligado à justeza do acordo interpessoal sobre o uso e o sentido dos diversos termos empregados 
neste ou naquele ambiente. O que se pretende ressaltar é que os atos pragmáticos apontam para o outro lado do axioma, ou seja, a possibilidade de nãocomunicação como regra assim definida:

a) não entender a mesma coisa;

b) não dizer a mesma coisa;

c) não se fazer entender da mesma maneira.

O que está em jogo é o que Mey (2003, p. 333-5) chamou de "O espectro da ambiguidade", ou seja: a busca pelos enunciados não-ambíguos é algo enraizado em nossa cultura; embora, geralmente, as pessoas não dêem respostas diretas do tipo "sim" ou "não" e façam longas digressões acerca do que é alguma coisa. Há tantas possibilidades de respostas quanto forem os indivíduos e suas crenças em uma situação comunicativa concreta; apenas em ocasiões muito específicas temos que jurar por Deus e responder afirmativamente ou negativamente sem enveredar por explicações que poderão comprometer a nossa situação diante da justiça divina ou dos homens. A ideia é a de que os fatos estão diante dos nossos olhos e a comunicação é uma questão de apanhálos e enviá-los por meio de um conduit (REDDY, 1979) que liga a minha cabeça à cabeça do interlocutor.

"Naturalmente, todos estão conscientes de que as pessoas comunicam algo mais e outras coisas além dos fatos: eles compartilham emoções, desejos, dão ordens e assim por diante; 'fazem coisas com as palavras' - coisas que não são reduziveis aos fatos. Mas a razão pela qual os fatos constituem tal inelutável alegação cega do nosso pensamento a respeito da comunicação é que nós não estamos negligenciando os fatos em si mesmos, mas o contexto em que eles ocorrem." (MEY, 2003, p. 336, tradução e grifo meus)"'.

A discussão a respeito do contexto se tornou a "pedra no sapato" da maioria dos debates sobre a produção de sentidos na atualidade. Por exemplo, a expressão "fora do contexto", que ouvimos com frequência, reforça a ideia de que há um conjunto de dados à espera do interlocutor, que deverá ser perspicaz o bastante para perceber os indícios fornecidos pelo locutor/texto e associá-los às informações pré-existentes a fim de elaborar um quadro de referências em que possa processar cognitivamente a interpretação. Evidentemente, essa noção não faz justiça à complexidade envolvida na negociação entre os pares; embora não descarte a ideia de que os indivíduos têm intenções que buscam tornar conhecidas e objetivos que desejam concretizar nas interações. O problema é definir qual o contexto do contexto? Isto é, como estabelecer uma noção de trabalho para contexto que dê conta dos múltiplos cenários (realidade semiotizada) que

1 Bakhtin (1988, p. 95) observou: “Na realidade, não são palavras o que pronunciamos ou escutamos, mas verdades ou mentiras, coisas boas ou coisas más, importantes ou triviais, agradáveis ou desagradáveis etc. A palavra está sempre carregada de um conteúdo ideológico ou vivencial. É assim que compreendemos as palavras e somente reagimos àquelas que despertam em nós ressonâncias ideológicas ou concernentes à vida." 
os indivíduos articulam na dinâmica social para expressar suas crenças diante de outras crenças, num fluxo interminável de posições avaliativas sem cair em um empiricismo atomicista ou em um idealismo transcendentalista?

Mesmo que a dependência de uma noção de contexto seja um ponto central para a abordagem pragmática, verifica-se que os requisitos para se elaborar tal conceito não são absolutamente determináveis; embora afetem de modo relevante todos os atos comunicativos. Coulter (1994, p. 689) ressalta que o termo contexto é um dos mais utilizados e injuriados nas ciências humanas e sociais. Como não há uma definição consensual a respeito, vamos estabelecer uma analogia entre a noção de contexto e a figura mitológica chamada Proteu, com o objetivo de elaborar uma definição de trabalho. Proteu, filho do Oceano, era famoso por suas metamorfoses e tomava a forma que desejasse de acordo com as circunstâncias e intenções. Diz a lenda que para fazê-lo falar era preciso surpreendê-lo em pleno sono e amarrá-lo de maneira que não pudesse escapar. Encarado dessa forma, o contexto deve ser visto diferenciadamente em cada linguagem (o quadro semântico-ideológico) e sempre resistindo firmemente às tentativas de ser aprisionado, isto é, confinado em um ambiente hermético. O contexto transforma-se e, ora é evanescente, ora é materialidade, mas conforme as crenças e costumes de cada comunidade linguageira.

O contexto é o mundo, uma realidade aberta e flexível que os indivíduos recortam, embora sem perceber que não são os dados puros que focalizam, mas a refração semiotizada de sua práxis social. Em si, a noção de contexto é uma abstração, e os indivíduos estarão focalizando a atenção e levando em conta os fatores situacionais (mundo sociocultural); elementos cognitivos (conceitualização) e os aspectos emotivos (afeto e envolvimento) que pertencem ao mundo mental (VERSCHUEREN, 1999, p. 90). Isso não restringe a noção de contexto ao conhecimento de mundo dos indivíduos, embora tal conhecimento seja importante quando se trata da previsibilidade ou imprevisibilidade das informações. Mas nem o contexto se reduz ao conhecimento de mundo, como o conhecimento de mundo não se reduz a essa dualidade informativa.

Desse modo, a noção de contexto vai além da ideia de referência e entendimento do que "as coisas do mundo real são", pois incorpora os aspectos da psique humana que têm nas expectativas, interesses, reivindicações, medos, anseios, atitudes, o seu ponto de convergência. Daí a necessidade de determinar ao interlocutor quais são as regras que estão sendo seguidas a cada mudança de nível de compreensão (a cada mudança de contexto psicológico). Obviamente, os comportamentos psicológicos individuais não têm uma origem pré-social, e devem ser traduzidos a partir das crenças morais que compartilham e adotam. Pragmaticamente, os indivíduos criam contextos e são criados por eles em uma troca incessante, uma espécie de re-criação onde é preciso investigar as metáforas em ação:

a) o que as metáforas expressam; 
b) como elas expressam aquilo que pretendem expressar;

c) qual é o grau de compatibilidade que têm com as circunstâncias e indivíduos;

d) de que forma elas contribuem para comunicar.

$\mathrm{Na}$ atualidade, a noção de contexto ganhou forte impulso com a ideia de que tecnicamente, pelo fato da interligação global de todas as máquinas na rede virtual, há um imenso hipertexto vivo compartilhado por todos os participantes da interação. Virtualmente, o hipertexto corre em todas as direções e constitui uma forma de macrocontexto saturado de links que permitem aos usuários saltar de uma informação para outra, de uma mídia para outra indefinidamente. Nesse macrocontexto, os usuários podem mesclar informações e procedimentos de naturezas diversas de forma dinâmica, a fim de organizar, compreender, estabelecer hipóteses, inferências, previsões, especificações etc. A configuração desses "saltos" reproduz, ainda que de forma precária, a dinâmica dos processos cognitivos humanos, entendidos como forma de "organizar o conhecimento convencional de mundo em conjuntos bem interligados" (GARRAFA, apud $\mathrm{KOCH}, 1989$, p. 64). No entanto, é preciso ressaltar que o fato de o hipertexto se apresentar como um cenário da diversidade humana, atrelado diretamente a uma comunidade de falantes, encerra a sua própria contradição. Ou seja: é exatamente nesse ambiente virtual, impregnado de cenários, que o texto rompe o vínculo com o ambiente em que surgiu. É possível afirmar que todo signo linguístico encontra-se em uma situação de ruptura com o ambiente de criação e que não deva nenhum respeito ao autor. Mas, “(...) isto não supõe que a marca valha fora do contexto mas, ao contrário, que só existem contextos sem nenhum centro absoluto de ancoragem" (DERRIDA, 1990, p. 25). Assim, uma noção de trabalho para contexto deve levar em conta a dinâmica do processo de significação onde os interlocutores consideram:

a) os aspectos imediatos, contingentes ou históricos da situação;

b) os aspectos psicológicos relacionados à memória, emoção, afeto, motivação, cognição etc.;

c) os costumes enquanto manifestações de crenças (regras para a ação) ${ }^{2}$;

o vocabulário de ações intencionais;

e) o grau do acordo feito entre os interlocutores sobre o sentido dos termos empregados;

f) o grau de conhecimento compartilhado entre os interlocutores, suas crenças, e as expectativas que decorrem dessa relação.

Também, torna-se necessário reinterpretar constantemente os sentidos gera-

2 Chamo a atenção para os costumes dos grupos (tribos) a que pertencem os indivíduos. As determinações dos grupos (o plano micro) muitas vezes se apresentam de formas atípicas em relação ao conjunto da sociedade (plano macro). Ou seja, no processo de construção identitária, as determinações e decisões dos grupos em que estão inseridos os indivíduos acabam sendo prioritárias em relação a outras esferas de influência social. 
dos pelo uso do termo contexto nas circunstâncias comunicativas e verificar como as pessoas "produzem e consomem" a linguagem; depois, alertar aos interlocutores que sem as conexões acima expostas é pouco provável que participem do contexto alheio.

Qualquer tentativa de definição linear de contexto está fadada ao insucesso, pois a noção não se resume ao que é "dado" e "escolhido" pelos indivíduos nas interações. Envolve uma ampla consideração do background linguístico e cognitivo dos interlocutores, além de remeter para uma questão hoje bastante criticada: a cooperação. A cooperação não é a comunicação, mas pode levar a ela a partir da premissa de que é preciso colaborar para se estabelecer um cenário comum que garanta, minimamente, as relações sociais. Quer dizer, a cooperação, e não a solidariedade como desejam Mey (1987) e Rorty (1994), ainda é a saída para se aproximar do "como" e "por que" o indivíduo usou a linguagem nesta e naquelas circunstâncias. Vivemos em uma sociedade de classes e a desigualdade social é imensa. Mas isto não implica em substituir a cooperação pela solidariedade, pois incorremos no erro de obliterar as razões práticas e os interesses pelos quais nos movimentamos socialmente, convergindo para um discurso piegas e politicamente correto que responde atualmente por um jogo de simulações.

\section{Então}

Podemos permanecer em um estado que Rajagopalan (2003, p. 83) chamou de "um saudosismo velado em relação à chamada linguagem adâmica, a linguagem em sua forma cristalina, quando substantivos seriam todos nomes próprios - posto que Adão escolhia cada palavra para nomear um único bicho a cada vez" e continuarmos a falar como se estivéssemos sido atacados por uma espécie de amnésia, empregando colóquios automáticos típicos de uma conversa de "salão de chá" (McLUHAN, 1977, p. 18) ou, finalmente, entender que as mudanças súbitas e frequentes no mundo atual exigem outras regras de uso para a linguagem. Um projeto realizável para lidar com a nova realidade é instituir uma "política para os performativos" que coloque sob suspeita as metáforas em uso nas instituições, inspirando os indivíduos a investigar como os hábitos linguísticos institucionais alteram e (de)formam os sentidos das palavras ordinárias, com resultados imediatos em suas vidas privadas. Além disso, é necessário refletir sobre as respostas (sentidos) que os integrantes de cada instituição dão para as diferentes ressonâncias ideológicas (crenças) em uso nesses ambientes. Metodologicamente, na política dos performativos, a questão central é como se posicionar diante de forças ilocucionárias que, ora conferem poder e privilégios aos indivíduos, ora os priva desses privilégios, conforme as mudanças e caprichos das políticas institucionais.

Essas iniciativas exigem que as pessoas iniciem um debate sobre/em a linguagem em uso nesses contextos como se estivessem discutindo os fonemas de um poema. Se a verdade é a experiência vivida, como queria Wittgenstein, en- 
tão é necessária uma ação constante para redescrever os hábitos e sentidos ou os sentidos dos nossos hábitos. Como fazer esta reflexivação? Cada indivíduo, como parte de uma instituição, primeiro deve olhar para o próprio "nariz" e buscar em sua conduta um motivo para se redescrever de uma outra forma, escolher novos vocabulários para as suas ações. Com este procedimento, a frase "O departamento de comunicação é um hospício!” poderá ser usada em outro jogo linguístico em que as metáforas não apontam para situações mórbidas ou patológicas, mas para um referente sadio. Afinal, a palavra "hospício" tem origem na palavra latina "hospes", que também deu origem a hospitalidade e hospedaria (abrigo). A escolha é sempre uma questão ética; os referentes, políticos! Nesse aspecto, não temos enunciados "bem-ditos" ou "mal-ditos", pois esse tipo de consideração apenas indica o caráter abstrato com que são descritas as situações causais e de comportamento humano. Os sentidos são decorrentes do uso, do modo de usar a linguagem em diferentes contextos relacionais e qualquer "explicação" encontra-se nessa dependência.

\section{Referências}

BAKHTIN, M. Marxismo e Filosofia da Linguagem. SP: Hucitec, 1988.

BARTHES, Roland. Mitologias. 9. ed. São Paulo: Bertrand Brasil, 1993.

BOURDIEU, Pierre. Outline of a Theory of Practice. Cambridge: Cambridge University press, 1977. . The Logic of Practice. Stanford: SUP, 1990.

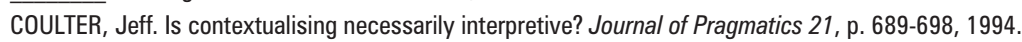

DASCAL, Marcelo. Two modes of understanding: compreending and grasping. Campinas: texto mimeo., [19--].

DERRIDA, Jacques. Gramatologia. São Paulo: Perspectiva, 1973.

. Limited Inc. Campinas: Papirus, 1990.

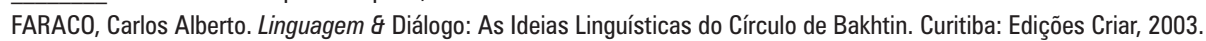

GRICE, H.P. Logis and conversation. In: COLE, P.; MORGAN, J. (Eds.). Syntax and semantics 3: Speech acts. New York: Academic Press, 1975.

KOCH, Ingedore. Texto e Coerência. São Paulo: Cortez, 1989.

LEVINSON, Stephen. Pragmatics. Cambridge: Cambridge University Press, 1993.

LÉVY, Pierre. Cibercultura. São Paulo: Editora 34, 1999.

MARCONDES Filho, Ciro. Até que ponto, de fato, nos comunicamos? São Paulo: Paulus, 2004.

McLUHAN, M.; WATSON, W. Do Clichê ao Arquétipo. Rio de Janeiro: Editora Record, 1977.

MEY, Jacob. Whose Language? Amsterdan: Benjamins, 1985.

. Pragmatics: an Introduction. London: Blackwell, 1993.

. Vozes da Sociedade. Campinas: Mercado das Letras, 2001.

. Context and (dis)ambiguity: A Pragmatic View. Journal of Pragmatics 35, p. 331-347, 2003.

Poet and Peasant: A Pragmatic Comedy in Five Acts. Journal of Pragmatics 11, 1987, p.281-297.

MOESCHLER, Jacques; REBOUL, Anne. Dictionnaire encyclopédique de pragmatique. Paris: Seuil, 1994.

MORRIS, Charles. Foundations of the Theory of Signs. Chicago: The University of Chicago press, 1938.

OLIVEIRA, Jair Antonio de. Comunicação e educação. Curitiba: Editora, Protexto, 2001.

. A Linguagem nas organizações. Porto Alegre: Congresso Brasileiro de Ciências da Comunicação, XXVIII INTERCOM, 2004.

Por uma Comunicação organizacional Mestiça. 2007. Disponível em: <www.bocc.ubi.pt>. Acesso em: 20 ago. 2009.

RAJAGOPALAN, Kanavillil. Por uma Pragmática Voltada à prática Linguística. In: ZANDWAIS, A. (Org.).Relações entre Pragmática e Enunciação. Porto Alegre: Sagra Luzzato, 2002.

. Por uma Linguística Crítica. São Paulo: Parábola, 2003.

. A Linguística que nos faz falhar. São Paulo: Parábola, 2004. 
. A Geopolítica do Inglês. São Paulo: Parábola, 2005.

REDDY, M. J. The conduit metaphor. In: ORTONY, A. (Ed.). Metaphor and Thought. Cambridge: Cambridge University press, 1979. p. 164-201.

RORTY, Richard. Contingência, Ironia e Solidariedade. Lisboa: Editoria Presença, 1994.

. Ensaios sobre Heidegger e outros. Rio de Janeiro: Relume-Dumará, 1999.

. Objetivismo, Relativismo e Verdade. Rio de Janeiro: Relume-Dumará, 1997.

SARANGI, Skrikant; SLEMBROUCK, Stefan. Language, Bureaucracy and social control. London: Longman, 1996.

SEARLE, John. Os Actos de Fala. Coimbra: Almedina, 1984.

SHIBLES, Warren. Wittgenstein, Linguagem e Filosofia. São Paulo: Cultrix, 1974.

VERSCHUEREN, J. Understanding Pragmatics. London: Arnold, 1999.

WATZLAWICK, Paul. Pragmática da Comunicação Humana. São Paulo: Cultrix, 1967.

WEIL, Pierre; TOMPAKOW, Roland. 0 Corpo Fala: a linguagem silenciosa da comunicação não-verbal. Petrópolis: Vozes, 1973.

WITTGENSTEIN, Ludwig. Investigações Filosóficas. Lisboa: Fundação Calouste Gulbenkian, 1985. 